\title{
A Study on Characteristics of Burn Patients Who were Admitted to a Tertiary Care Hospital in the Southern Province Of Sri Lanka
}

Chithrani WA, Ruwanpura PR

Office of the Judicial Medical Officer, Teaching Hospital Karapitiya, Sri Lanka

\begin{abstract}
Introduction: A burn is a type of injury to the skin, or other tissues, caused by heat, cold, electricity, chemicals, friction or radiation. It is a significant health hazard worldwide. According to the annual health bulletin 2015 in Sri Lanka, burn injuries responsible for $7.2 \%$ of all traumatic admissions per year. Most of them appeared to be preventable. The study was conducted to determine socio-demographic characteristics of patients with burn injuries, different circumstances, types of causative agents, knowledge about the first aids available, morbidity and mortality of patients.
\end{abstract}

Methodology: Data including age, sex, circumstances, burn agent, the incidence, first aid and details about arrival to the hospital were collected from June 2017 to July 2019 by an interviewer based questionnaire. The nature of burns and the total body surface area (TBSA) were determined by clinical examinations. The information regarding the management of the patients, length of hospital stay, complications developed and the outcome of the patient at discharge from the hospital was collected from Bed Head Tickets. Long term complications were observed and noted when patients visit the occupational therapist for rehabilitation. Anonymous data were entered in an Excel sheet and analyzed by SPSS software.

Results: Majority (62\%) were from lower-middle social class. Majority of burn injuries (65\%) are due to accidental burns. Commonly affected age group is the pediatric age group (32\%). The commonest causative agents are hot water and other hot liquids (49\%). Carelessness of handling thermal agent and non-anticipation of injuries by caregivers of children were identified as main causes for burn injuries. Even though $58 \%$ of patients were giving some kind of first aids following a burn, knowledge about correct methods of the first aid was minimal. Self-inflicted burn injuries accounted for $25 \%$ of cases and06\% accounted for injuries due to chemical assaults. The mean surface area (TBSA) of burnswas $14 \%$ and the depth of the burn depended on the causative agent and the condition of the given first aid. Of them, $27 \%$ of injuries were categorized as non-grievous, $58 \%$ as grievous, $13 \%$ as Fatal in the ordinary cause of nature and $02 \%$ as necessarily fatal.

Conclusion: Burn injuries account considerably to the morbidity and mortality in the surgical wards. Majority of burns are due to accidental causes. They are preventable by careful handling of hot agents and electricity and taking precautions to prevent injuries by caregivers of children. The knowledge of correct methods of the first aids among people is very low. By giving proper first aids reduces the depth of wound and thereby, the hospital stay can be reduced.

Keywords: Burn injury, Accidental burn, Pediatric burn.

Received: 02 Nov 2019, Revised version accepted: 20 Jan 2020, Published: 30 June 2020. *Corresponding author: Chithrani WA, $\triangle$ Email: wachithrani@gmail.com, (D) ORCID https://orcid.org/0000-0002-9646-5739

Cite this article as: Chithrani WA, Ruwanpura PR. A study on characteristics of burn patients who were admitted to a tertiary care hospital in the southern province of Sri Lanka. Medico-Legal Journal of Sri Lanka. 2020;8(1):8-14. DOI: http://doi.org/10.4038/mljsl.v8i1.7403

Copyright: @ 2019 with the Medico-legal Journal of Sri Lanka.

This is an open-access article distributed under the terms of the Creative Commons Attribution 4.0 International License, which permits unrestricted use, distribution and reproduction in any medium provided the original author and source are credited.

\section{Introduction}

There is evidence to support that the management of burns has been started since ancient time. As examples, paintings at caves more than 3,500 years ago documented the burns and their management. ${ }^{[1]}$ The earliest Egyptian records on treating burns explained dressings prepared with milk from mothers of baby boys. ${ }^{[2]} \mathrm{In}$ 1500 BCE Edwin Smith Papyrus describes treatments using bee honey and the salve of resin. ${ }^{[1]}$ The Chinese documented usage of tea leaves in 600 BCE. Hippocrates described the usage of pig fat $\&$ vinegar in $400 \mathrm{BCE}^{[1]}$ French barber-surgeon Ambroise pare first described in the 1500s different degrees of burns. ${ }^{[1]}$ 
A burn is defined as an injury to the skin or other tissues by heat, cold, electricity, chemicals, friction or radiation. ${ }^{[1]}$

World Health Organization data recognize "burn" as a global public health problem, accounting for an estimated 180000 deaths annually. ${ }^{[3]}$ Most burns have been identified in low- and middle-income countries. ${ }^{[3]}$

Mortality from burns is significantly lesser in high income countries. Compared to high-income countries death rate from burns in the pediatric population is seven times higher in low-income countries. ${ }^{[3]}$

Non-Fatal burns cause significant morbidity, including prolong hospital stay \&scaring. South Asian countries bear a significant burden of injury due to burns. Estimates of incidence of burn injuries in India vary from 100000 to 2 million annually, of which 50000 are estimated to be fatal. In Pakistan, burns are the second leading cause of disability and the $11^{\text {th }}$ leading cause of premature deaths. In Sri Lanka, nearly 10000 injuries and 100 deaths are burn related, costing U\$\$1 million annually. ${ }^{[4]}$

A study ${ }^{[5]}$ done at a general hospital of Eastern province of Sri Lanka have shown that $64 \%$ of burns were accidental, and $25 \%$ were self-inflicted. The rest included assaults \& undetermined cause. Fall of a homemade kerosene bottle lamp accounted for $41 \%$ of accidental burn. The flame was the leading cause, followed by scalds. Females were the main victim of burns in most of the cases except in injuries from assault. Children between 1 and 4 years old were at high risk for accidental burn, especially from scalds. Women (Age between 20-29 years) had the highest percentage of self-inflicted burns. Self-inflicted burns were more extensive and fatal than accidental ones. The mortality rate of selfinflicted burns was $27 \%$. When the burnt area is $>50 \%$, it is invariably fatal. The elderly \& age between 20-29years was the people who had the highest mortality.

A studydone at National Hospital of Sri Lanka regarding burns due to acid assaults has shown that out of all patients with burns, 46 were due to acid assaults, which was $4 \%$ of the total number of burn patients during the period. ${ }^{[6]}$ The age ranged from 12 to 60 years, and most patients $(63 \%)$ were between 21 and 40 years. The male to female ratio was 2.8:1. In acid, burns mortality was low (4.34\%) when compared to flame burns. Formic acid was the most prevalent causative agent $(41 \%)$. Face $(93 \%)$, chest $(65 \%)$, and upper limbs (64\%) were the commonly involved areas in acid burns.
Management of burn patient must be a multidisciplinary approach including a plastic surgeon, physician, and pain managing team, psychologist, nutritionist and social worker. But in Sri Lanka, There are no well-established burns units all over the country. Most of the units still use old methods of wound management methods which are much painful and patients will end up with depression-like psychological problems in adults \& children will become aggressive when they discharge from the hospital after long term suffering. Even though there are new sophisticated dressings available in the private sector, most of the time it is not affordable for the people in a third world country like Sri Lanka. Most burn injuries are accidental. So they can be prevented by simple educational programs. Also, the extent of burn can be reduced by using simple first aids methods. This study was conducted to determine sociodemographic characteristics of patients with burn injuries, different circumstances, types of causative agents, knowledge about the first aids available, morbidity and mortality of patients.

\section{Methods}

The study sample size was calculated according to the standard equation $(n=325)$. Readmissions for the same wound, referrals from other institutions for scar and contracture management were excluded. It was taken two years to complete the sample.

Data including age, sex, circumstances, burn agent, the incidence, first aids, and details about arrival to the hospital were collected from June 2017 to July 2019 by an interviewer based questionnaire. The nature of burn sand the total body surface area (TBSA) were determined by clinical examinations. The information regarding the management of the patients, length of hospital stay, complications developed and the outcome of the patient at discharge from the hospital was collected from Bed Head Tickets. Long term complications were observed and noted when patients visit the occupational therapist for rehabilitation. Anonymous data were entered in an Excel sheet and analyzed by SPSS software.

Data were collected by recording answers from interviewer administered questionnaire from the patient or guardian, Examination of patents, information of Bed Head Tickets, follow up of patients while attending to rehabilitation clinics. Collected anonymous data were entered into an Excel sheet and analyzed using SPSS (IBM version25) software.

Ethical approval for the research proposal was taken from ethical review committee at the Faculty of Medicine, University of Ruhuna. Also the proposal 
was approved by the Board of study of Forensic Medicine of Post Graduate Institute of Medicine.

Results

Socio-demographic profile

Out of 325 patients, $71 \%$ were females $(n=232)$.

Table 01(a): Age distribution of patients

\begin{tabular}{lr}
\hline Age (years) & $\begin{array}{r}\mathbf{N}=\mathbf{3 2 5} \\
\mathbf{n}(\boldsymbol{\%})\end{array}$ \\
\hline$<13$ & $103(32)$ \\
$13-20$ & $32(10)$ \\
$21-30$ & $45(14)$ \\
$31-40$ & $73(22)$ \\
$41-50$ & $30(09)$ \\
$51-60$ & $24(07)$ \\
$>60$ & $18(06)$ \\
\hline
\end{tabular}

Of them $32 \%(n=103)$ belonged to the pediatric age group and it was the highest.

Table 01 (b): Age distribution among the pediatric age group

\begin{tabular}{lr}
\hline Age range & $\begin{array}{r}\mathbf{N}=\mathbf{3 2 5} \\
\mathbf{n}(\boldsymbol{\%})\end{array}$ \\
\hline 0-6months & $43(04)$ \\
6months-1year & $92(08)$ \\
1year-4years & $187(17)$ \\
4years-8years & $361(33)$ \\
8years-12years & $313(28)$ \\
\hline
\end{tabular}

Among pediatric group majority was infants $(<1$ year) which was $58 \%(n=60)$. Out of them, $40 \%$ was less than 6 months \& $60 \%$ more than 6 months.

\section{Manner of incidents}

Majority of incidents are due to accidental causes. It accounts for $65 \%(n=211)$ of the total. Then selfinflicted or suicidal attempts which is $25 \%(\mathrm{n}=81)$ of the total number. There were $6 \%(n=19)$ due to assaults \& $4 \%$ of cases were doubtful. Table 02 shows the manner of incidents.

Table 02: Distribution of the manner of incidents

\begin{tabular}{lr}
\hline Manner of incidents & $\begin{array}{r}\mathbf{N}=\mathbf{3 2 5} \\
\mathbf{n}(\boldsymbol{\%})\end{array}$ \\
\hline Accidental & $211(65)$ \\
Self-inflicted & $81(25)$ \\
Assaults & $19(06)$ \\
Doubtful & $14(04)$ \\
\hline
\end{tabular}

\section{Socio economic distribution}

There is a research article in the "KALAM" International journal of Faculty of Arts and Culture, South Eastern University of Sri Lanka ${ }^{[7]}$, regarding methodology of classification of socioeconomic classes in Sri Lanka in $21^{\text {th }}$ century. According to that Sri Lanka's social structure is based purely on money and power consequently. There is mainly four social classes. ${ }^{[7]}$ They are 1 . Upper social class, 2. Upper middle class, 3. Lower middle class and 4. Lower or poor social class.

For development of this classification, the researcher has been gathered data from various resources of the secondary information schemes such as published journals, articles, books and electronic documents. The primary data also has been gathered from the structured interview with key informants. The following groups of people were interviewed as key informants; Academics; Religious leader; Experienced people. This paper analyzes the data of social stratification along the lines of organizational theory and relevant published materials.

Table 03: Socio economic distribution among burn patients

\begin{tabular}{lr}
\hline Social class & $\begin{array}{r}\mathbf{N}=\mathbf{3 2 5} \\
\mathbf{n}(\boldsymbol{\%})\end{array}$ \\
\hline Upper & $04(04)$ \\
Upper middle & $55(14)$ \\
Lower middle & $201(62)$ \\
Lower & $65(20)$ \\
\hline
\end{tabular}

According to the data, $62 \%(n=201)$ were from the lower middle class.

There were $20 \%(\mathrm{n}=65)$ from the lower class followed by upper-middle-class $14 \%(n=55)$. There were $4 \%(n=4)$ from the upper social class.

\section{Places of occurrence}

Out of all, 52\% (169) were happening at home or house premises. $40 \%$ (130) were taken place as occupational injuries, other $8 \%(n=66)$ included open places like roads, hotels, schools etc. Table 04 shows the places of occurrence.

Table 04: Places of incidents are happening

\begin{tabular}{lr}
\hline Place of incidents & $\begin{array}{r}\mathbf{N = 3 2 5} \\
\mathbf{n}(\boldsymbol{\%})\end{array}$ \\
\hline At home & $169(52)$ \\
At work place & $130(40)$ \\
Others & $66(08)$ \\
\hline
\end{tabular}

Types of burn

Table 5: causative agents for burns

\begin{tabular}{lr}
\hline Causative agent & $\begin{array}{r}\mathbf{N = 3 2 5} \\
\mathbf{n}(\boldsymbol{\%})\end{array}$ \\
\hline Hot water & $89(27)$ \\
Flame & $83(25)$ \\
Hot liquids & $71(22)$ \\
Contact with thermal objects & $51(16)$ \\
Chemical agents & $16(05)$ \\
Electrocution & $08(03)$ \\
Others & $07(02)$ \\
\hline
\end{tabular}


According to the data of this study, the comments injurious agent in burn is hot water. It accounts for $27 \%(n=89)$ of total burn patients. Fire related burns including accidental falling of kerosene oil lamps, catching fire while cooking with fire hearths and gas stoves, catching fire while doing cleaning works at home premises etc. They account for $25 \%(n=83)$ of the total number of patients. Other hot liquids include hot coconut oil, hot tar, hot beverages and melted plastic. They account for $22 \%(n=71)$ of the total number of patients. Contact thermal agents include contact with a hot iron, silencer burn, and machine-related burn while in occupation, etc. It Includes $16 \%(\mathrm{n}=51)$ of total patients. Acids and alkaline agents account for $5 \%(n=16)$ of the total number of patients. One of them was splashing of acid over the anterior chest while trying prevention of self-ingestion of sulfuric acid. Electrocution related burns accounts for $3 \%(n=8)$ of patients. One was a deceased person following high-tension electrocution while reconnecting electric current. Others were flash burn and arc burn related to occupational work. Remaining other causes include (2\%), burn injuries following lightening, friction burn in road traffic accidents.

\section{The affected area of the body}

It varies with several variables.

Table 06 shows distribution of area of body surface according to the manner of incidences and causative agent.

According to the results, accidental burns happen by spillage of hot water, spillage of other hot liquids other than hot water, contact thermal burn, electrocution burn and flame burn. Other than these, few cases of friction burns during road traffic accidents were there. Out of all 89 patients of accidental hot water burns $54 \%(\mathrm{n}=48)$ were involve anterior chest, $22 \%(\mathrm{n}=20)$ involve only hands, $15 \% \quad(n=13)$ include anterior chest and anterior abdomen, $8 \%(n=7)$ involve lower limbs and only one case involves external genitalia and inner aspects of upper thigh.

Hot tea, hot coconut oil, hot tar, hot beverages were identified as hot liquids other than hot water. The total number of patients includes 71 . Out of them, $48 \%$ of patients presented with a splashing of hot liquid onto the body, 39\% cases showed with spillage of hot liquid onto the limbs \& $13 \%$ presented with spillage onto the abdomen. (Table 06)
Table 06: Involved body surface according to the manner of incidents

\begin{tabular}{|c|c|c|}
\hline Manner of incidents & $\begin{array}{r}\text { Area } \\
\text { involved }\end{array}$ & $\begin{array}{l}\mathrm{n}=325 \\
\mathrm{n}(\%)\end{array}$ \\
\hline Accidental hot water & 3 & $54(48)$ \\
\hline burn & $\begin{array}{r}2 \\
3+6 \\
5 \\
7+5\end{array}$ & $\begin{array}{r}22(20) \\
15(13) \\
08(07) \\
01(01)\end{array}$ \\
\hline $\begin{array}{l}\text { Accidental hot liquid } \\
\text { burn other than hot } \\
\text { water }\end{array}$ & $2+5$ & $39(28)$ \\
\hline Splash on to the body & 6 & $\begin{array}{l}48(34) \\
13(09)\end{array}$ \\
\hline Electrocution burn & $\begin{array}{r}2 \\
2+3+5+6\end{array}$ & $\begin{array}{l}50(04) \\
25(02)\end{array}$ \\
\hline Flash burn & & $25(02)$ \\
\hline Self-inflicted burn & $\begin{array}{r}1+2+3+5+6 \\
1+2+3 \\
2+3+6\end{array}$ & $\begin{array}{l}21(17) \\
49(40) \\
28(23)\end{array}$ \\
\hline Acid spillage & & $01(01)$ \\
\hline
\end{tabular}

There were $15.6 \%(n=51)$ of contact thermal burn. There was no specific pattern identified.

There were 81 cases with self-inflicted burn injuries. Almost $98 \%(n=80)$ of them used to fire with kerosene oil or petrol. There $49 \%(n=40)$ of cases involve the anterior neck, anterior chest and bilateral hands. Hands involvement is due to trying by them to control the fire. $28 \%$ of cases include anterior chest abdomen and hand without neck or face involvement. In $21 \%(\mathrm{n}=17)$ cases were involved the face, anterior chest bilateral upper limbs and lower limbs. Only one case (2\%) admitted with spillage of acid while trying to prevent self-ingestion (Table 06). 
The distribution of the burnt surface area The involved burn surface area was calculated by using Wallace's rule of nine. The below picture demonstrate percentage of area over the body surface. ${ }^{[8]}$ Median TBSA is $14.5 \%$.

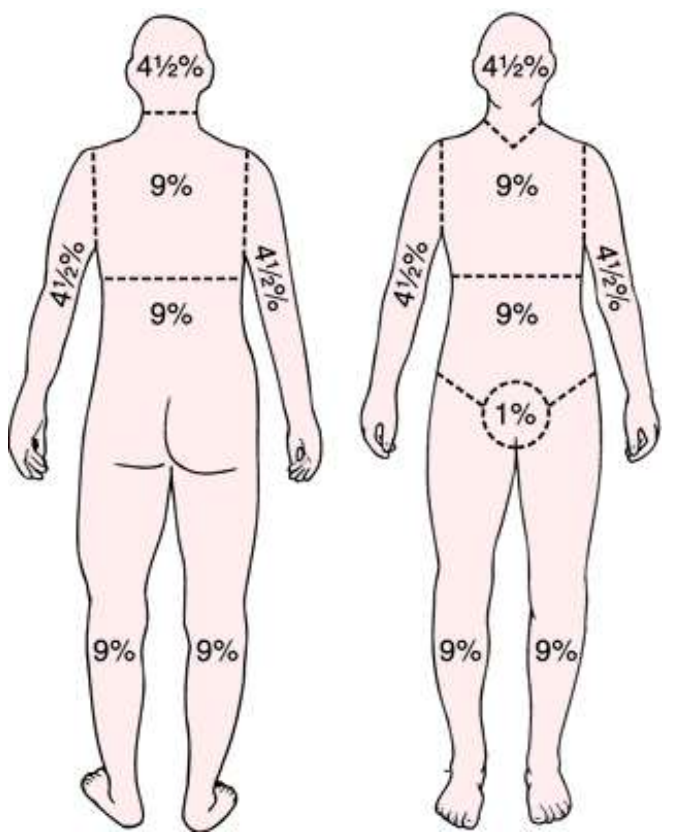

Figure 01: Wallace's rule of nine

Table 07: Distribution of mean body surface area with a causative agent of incidences

\begin{tabular}{lr}
\hline Causative agents & $\begin{array}{r}\text { Mean body surface } \\
\text { area \% }\end{array}$ \\
\hline Flame & 23 \\
Chemical & 14 \\
Hot water & 12 \\
Hot liquid & 07 \\
\hline
\end{tabular}

The highest median TBSA $23 \%$ is related to the flame burn. The median TBSA of $14 \%$ was related to the chemical burn. The median TBSA of $12 \%$ belongs to the hot water burn, $7 \%$ with hot liquid burn and $3 \%$ with thermal contact burn.

\section{Distribution of degree of burn with causative agent}

According to the results, the $1^{\text {st }}$-degree burn is most frequent with hot liquids other than hot water; 2nddegree burns are most prevalent with hot water burn. $3^{\text {rd }}$-degree burns are frequent with chemical burns, and $4^{\text {th }}$-degree burns are commonest with flame burn.
Table 08: Distribution of degree of burns with causative agents

\begin{tabular}{|c|c|c|c|c|}
\hline $\begin{array}{l}\text { Type of } \\
\text { burn }\end{array}$ & $\begin{array}{r}\text { FD } \\
\text { n }(\%)\end{array}$ & $\begin{array}{r}\text { SD n } \\
(\%)\end{array}$ & $\begin{array}{l}\text { TD } \\
\text { n }(\%)\end{array}$ & $\begin{array}{r}\text { FD } \\
\text { n }(\%)\end{array}$ \\
\hline $\begin{array}{l}\text { Flame burn } \\
\mathrm{N}=83\end{array}$ & $05(06)$ & $12(14)$ & $58(70)$ & $08(10)$ \\
\hline $\begin{array}{l}\text { Hot water } \\
\text { burn } N=89\end{array}$ & $29(32)$ & $41(46)$ & $19(21)$ & $\mathrm{No}$ \\
\hline $\begin{array}{l}\text { Hot liquid } \\
\text { other than } \\
\text { hot water } \\
\mathrm{N}=71\end{array}$ & $11(15)$ & $20(28)$ & $46(65)$ & No \\
\hline $\begin{array}{l}\text { Contact } \\
\text { thermal } \\
\mathrm{N}=51 \text {, }\end{array}$ & No & $23(45)$ & $28(55)$ & No \\
\hline $\begin{array}{l}\text { Electrocuti } \\
\text { on } \mathrm{N}=8\end{array}$ & No & $02(25)$ & $06(75)$ & $\mathrm{No}$ \\
\hline Others $\mathrm{N}=4$ & No & $03(75)$ & $01(25)$ & $\mathrm{No}$ \\
\hline
\end{tabular}

Attitude regarding first aid following burn Out of 325 patients, 189 patients were given some kind of the first aids, while 136 patients were not.

Table 09: Types of first aid given following burn

\begin{tabular}{lrrr}
$\begin{array}{l}\text { Manner of } \\
\text { incidents }\end{array}$ & $\begin{array}{r}\text { Cooling } \\
\mathbf{n = 4 0} \\
\mathbf{n}(\boldsymbol{\%})\end{array}$ & $\begin{array}{r}\text { Applica } \\
\text { tions } \\
\mathbf{n = 1 0 3} \\
\mathbf{n}(\boldsymbol{\%})\end{array}$ & $\begin{array}{r}\text { Applica } \\
\text { tion + } \\
\text { Cooling } \\
\mathbf{n = 4 6} \\
\mathbf{n}(\boldsymbol{\%})\end{array}$ \\
\hline Accidental & $22(55)$ & $64(62)$ & $19(41)$ \\
Self-inflicted & $08(20)$ & $22(21)$ & $06(13)$ \\
Assault & $09(22)$ & $11(11)$ & $18(39)$ \\
Doubtful & $01(03)$ & $06(06)$ & $03(07)$
\end{tabular}

Place of management in the hospital

Table 10: The location of management at the hospital

\begin{tabular}{|c|c|}
\hline Place of management & $\begin{array}{c}\mathrm{N}=325 \\
\mathrm{n}(\%)\end{array}$ \\
\hline At ETC, Then Discharge & $34(10)$ \\
\hline At surgical wards & $266(82)$ \\
\hline At isolation unit & $12(04)$ \\
\hline At ICU & $13(04)$ \\
\hline
\end{tabular}

All the patients with burn injuries were admitted to the Emergency Trauma Care Centre (ETC). Some patients were managing while at ETC ward and discharge. Then they are reexamining at the clinic. $10 \%(n=34)$ belonged to this category. Remaining patients were admitted to the surgical wards $82 \%$ 
$(n=266)$ and depending on the availability of beds, some critically ill patients were admitted to the ICU $4 \%(n=13)$ or Isolation unit $4 \%(n=12)$.

\section{Methods of management of patients}

It will be discuss in the discussion part of the article.

\section{Length of hospital admission}

The average length of hospital stay for a patient is 12days. (Minimum 1day to maximum 64 days).

\section{Types of complications during hospital admission}

Out of all patients, almost all suffered from pain. It was more severe in $2^{\text {nd }}$-degree burn $\&$ it is less in the 4th-degree burn. 102 patients developed culturepositive local wound infection with 54 swab cultures were positive for coliform bacteria while others positive for common skin flora. Only 19 patients developed culture positive bacteraemia. Sixteen patients were developed acute kidney injury, and 8 out of them ended up with acute renal failure. There were eight deaths following admission \& out of them, one from electrocution burn, seven from selfinflicted flame burns.

\section{Category of hurt}

Out of 325 patients, $27 \%$ ( $\mathrm{n}=87$ ) were non Grievous injuries.58\% $(n=190)$ were Grievous injuries. Most of the injuries become grievous because of their lengthier healing time and due to endangering life. There were $12.6 \%(n=41)$ of patients who were Fatal in the ordinary cause of nature. They had involved TBSA $45 \%$ to $60 \%$. $2 \%(n=08)$ were Necessarily Fatal as involved TBSA is more than $60 \%$.

\section{Discussion}

This study was carried out in a tertiary care Hospital in the Southern province of Sri Lanka. It included 325 patients following acute burns.

It focused on the significance of morbidity and mortality due to burn injuries, what are the circumstances of burn injuries, what are the risk factors, to which extent it is preventable, knowledge and attitude regarding first aids following burn injuries. $2 \%(n=8)$ of them died. Out of them, six were female. Almost death is due to self-inflicted flame burns. All of them have reached the hospital alive. But dying declaration (which is an integral part for medico-legal purpose) was not taken from either of them.

Considering circumstances of burn injuries, the majority were accidentally followed by selfinflicted, assaults\& doubtful cases.

Pouring of Hot water \& other liquids and use of traditional kerosene oil lamps were the main causative factors for the accidental burn. In a study done in India showed that one-third of accidental burns are due to clothing catching fire from open flames. ${ }^{[9]}$

In this study quarter, $25 \%(\mathrm{n}=81)$ of burns was selfinflicted and, $90 \%$ of them were female. Most of them were related to family inflicts due to extramarital affairs and low income of the family. Majority of them used kerosene oil or petrol as the igniting agent. But in a study done at Batticaloa in Sri Lanka reveled $41 \%$ of burns were self-inflicted. ${ }^{[5]}$ Nearly half of them were due to marital problems. A significant number of patients from the pediatric age group ( $<13$ Years) presented with burn injuries. Almost all pediatric burns were accidental. Out of all pediatric burn, nearly $1 / 3^{\text {rd }}$ were perambulatory age group ( $<6$ months).

Hot water \& other liquids accounted for almost half of burns and all were accidental. A quarter of burns were due to flame/fire. Except for one case, all others were due to assaults. The small proportion of burns $(5 \%)$ was due to acid \& alkali - most of the time, acetic acid used for assault. Freely availability (in rubber industry) may be the reason. Almost all patients with acid (or alkali) burns involved face, neck and upper chest. There was a difference in number of burn patients in various social classes. The majority was from the lower middle class. No cases were reported from the upper-middle class. This may be due to not presenting for the Government sector. A study done in Sri Lanka regarding acid burns reported $4 \%$ of all burns. The leading causative agent was formic acid in that study. [6] Availability of acids in the domestic environment may be the reason for the difference in the causative agent.

First aid is an essential element of initial resuscitation of burn injuries. Removal of cloths and cooling with running water 20 to 30 miutes is the recommended first aid method. It reduces the extent of burn further profoundly. But in Sri Lanka traditionally people use "komarika" and toothpaste for cooling purposes other than exposing the burn area to running water. In this study, $58 \%$ of burnt patients had done some cooling methods. Nearly three-quarter of them had used water as a cooling agent. But only the minority had exposed the burnt area to "running" water. No one did the cooling at least 20 minutes.

More than half of burns in this study were categorized as grievous. Prevention of attending for daily pursuits $>20$ days was the main factor for being categorized as grievous.

\section{Conclusion}

Accidental burns were the most frequent circumstance of burn injuries. The main causative 
agents were hot water or other hot liquids. The pediatric population was the most affected age group, while infants being the majority of them. Almost all were due to hot water. Almost all selfinflicted burns were due to flame burns \& females from the lower middle class were the main affected group. Acetic Acid was the commonly used chemical agent in acid assaults \&males are affected more than females. Proper first aid method had not been practiced by most of the patients. When considering the whole study, a female was the most vulnerable group in all circumstances of burns except assault.

\section{Recommendations}

Ensure careful handling of hot water \& other liquids to prevent accidental burns. Anticipate accidental burn injuries and take precautions when caring for children. Educate the population regarding adverse consequences of burn, including serious complications. Introduce and educate about proper first aid methods and its importance to reduce the severity of burns

\section{References}

1. Pećanac M, Janjić Z, Komarčević A, Pajić M, Dobanovački D, Mišković-Skeledžija S. Burns treatment in ancient times. Medicinski pregled. 2013;66(5-6):263-7.

2. Lee KC, Joory K, Moiemen NS. History of burns: The past, present and the future. Burns \& trauma. 2014 Oct;2(4):169.
3. Bergs J, Hellings J, Cleemput I, Zurel Ö, De Troyer V, Van Hiel M, Demeere JL, Claeys D, Vandijck D. Systematic review and metaanalysis of the effect of the World Health Organization surgical safety checklist on postoperative complications. British Journal of Surgery. 2014 Feb;101(3):150-8. 12.

4. Golshan A, Patel C, Hyder AA. A systematic review of the epidemiology of unintentional burn injuries in South Asia. Journal of public health. 2013 Jan 14;35(3):384-96.

5. Pirasath S, Jasotharan V, Jepara P. Burn injuries in the Eastern Province of Sri Lanka: analysis and outcome in a tertiary care hospital, Batticaloa. Sri Lanka Journal of Surgery. 2013 Aug 18; 31(2): pages.

6. Karunadasa KP, Perera C, Kanagaratnum V, Wijerathne UP, Samarasinghe I, Kannangara CK. Burns due to acid assaults in Sri Lanka. Journal of Burn Care \& Research. 2010 Sep 1;31(5):781-5.

7. Riswan M. A historical survey of social class and caste system in Sri Lanka.

8. National guidelines CSSL, Management of burn; 2007: page number 50.

9. Shankar G, Naik VA, Powar R. Epidemiological study of burn injuries admitted in two hospitals of north Karnataka. Indian journal of community medicine: official publication of Indian Association of Preventive \& Social Medicine. 2010 Oct;35(4):509. 